\title{
Pensando o teatro como lugar de detenção e a atuação como estado de suspensão e irradiação
}

\author{
Maritza Farías Cerpa \\ Mestranda em Artes Cênicas/USP \\ Área de Concentração: Pedagogia de Teatro \\ Orientador: Flávio Desgranges de Carvalho \\ Bolsista da Comisión Nacional de Investigación Científica y Tecnológica (CONICYT), do Governo \\ do Chile \\ Atriz chilena, diretora e docente teatral. Fundadora da Companhia de Teatro Lucidez Infante. \\ Pesquisadora do CEPECA - Centro de Pesquisa em Experimentação Cênica do Ator -, da \\ Universidade de São Paulo, coordenado pelo Prof. Dr. Armando Sergio da Silva.
}

Resumo: Este texto apresenta brevemente o projeto de mestrado Pensando o teatro como lugar de detenção e a atuação como estado de suspensão e irradiação - Uma proposta pedagógico-artística para o ator, baseado no diálogo da prática dos procedimentos de Michael Chekhov e na éticaestética proposta pelo Simbolismo de Maeterlinck, que visa oferecer uma possibilidade de criação cênica autoral do atuante. A pesquisa projeta a elaboração de um procedimento metodológico, concebido em um aprendizado sensível e técnico no processo de formação do ator, através de ferramentas práticas e concretas que expandam as potencialidades do corpo do ator. Como exteriorizar e fazer ver o movimento interior de um corpo? Como tornar visível o invisível? Como fazer presente o que aparentemente está ausente?

Palavras-chave: atuação, formação atoral, interpretação, Michael Chekhov

Title: Thinking of the theater as a place of detention and acting as a state of suspension and irradiation

Abstract: This text presents briefly the Masters' project Thinking of the theater as a place of detention and acting as a state of suspension and irradiation - A pedagogical-artistic proposal for the actor, based on the dialogue of Michael Chekhov's practice procedures and on the ethicalesthetic proposal for the Symbolism of Maeterlinck, that aims to propose a possibility of acting's authorial stage settings. The research projects the elaboration of a methodological procedure, conceived in the sensitive and technical learning in the actor's training, through practical and concrete tools that expand the skills and abilities of the actor's body. How can we externalize and show the inner movement of a body? How can we make visible the invisible? How can we make present what's apparently absent?

Keywords: acting training, actuation, interpretation, Michael Chekhov

Título: Pensando el teatro como lugar de detención y la actuación como estado de suspensión e irradiación

Resumen: Este texto presenta brevemente el proyecto de Magíster Pensando el teatro como lugar de detención y la actuación como estado de suspensión e irradiación - Una propuesta pedagógicoartística para el actor, basado en el diálogo de la práctica de los procedimientos de Michael Chekhov y en la ética-estética propuesta por el Simbolismo de Maeterlinck, que intentará proponer una posibilidad de creación escénica autoral del actuante. La investigación proyecta la elaboración de un procedimiento metodológico, concebido en el aprendizaje sensible y técnico en la formación del actor, a través de herramientas prácticas y concretas que expandan las habilidades y capacidades 
del cuerpo del actor. ¿Cómo exteriorizar y hacer ver el movimiento interior de un cuerpo? ¿Cómo hacer visible lo invisible? ¿Cómo hacer presente lo que aparentemente está ausente?

Palabras-clave: actuación, formación actoral, interpretación, Michael Chejov

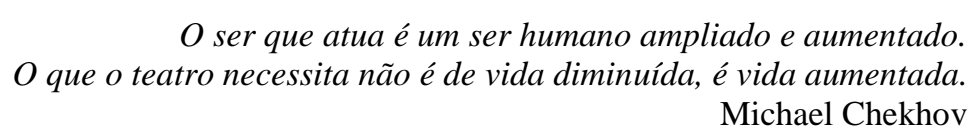

\section{Introduzindo}

O projeto de pesquisa Pensando o teatro como lugar de detenção e atuação como estado de suspensão e irradiação propõe a busca de uma possibilidade de criação cênica autoral do atuante, a partir de uma perspectiva pedagógico-artística.

A pesquisa está situada entre o diálogo da prática dos princípios técnicos atorais de Michael Chekhov e da ética-estética proposta pelo simbolismo de Maeterlinck, projetando a elaboração de um procedimento metodológico, concebido em um aprendizado sensível e técnico na formação do ator, por meio de ferramentas práticas e concretas que expandam as habilidades e capacidades do corpo do intérprete e permitam, em alguma medida, dar uma resposta corporal ao questionamento essencial de seu trabalho de atuação: como exteriorizar o movimento interior de um corpo? Como tornar visível o invisível? Como fazer presente o que aparentemente está ausente?

Esta pesquisa pretende abordar o trabalho do ator tanto do ponto de vista teórico quanto prática e, ao seu final, resultará em um espetáculo que tem o objetivo de traduzir cenicamente os procedimentos de trabalho da pesquisa como mostra de um possível caminho para a criação teatral.

Sempre que assistimos a um espetáculo ou um filme em que seres humanos "atuam", temos um "sobressalto". Inquieta-nos várias questões acerca do desenvolvimento da atuação enquanto arte. Como aquele que atua pode tornar visível o invisível? Pode-se desenvolver uma técnica que permita mostrar o estado interior do que estou "sendo" em cena? Como possibilitar ao espectador a captação imediata, direta, da mensagem que o ator quer transmitir? Como tornar concreto o abstrato, ou seja, pensamentos e emoções?

É algo difícil e muito complexo.

Refletindo sobre essas indagações, conclui-se que o único recurso que o ator dispõe para isso é o seu corpo. Ele é concreto e visível, é a única materialidade com a qual contamos para expressar o que permanece oculto no nosso interior. Para expressar, por exemplo, a solidão de um 
pensamento, a força das emoções, a rapidez das batidas de um coração em taquicardia. Pôr em evidência as reações, os movimentos e as ações físicas internas que se mobilizam por debaixo de nossa pele. É quase como se a nossa pele fosse transparente e pudéssemos ver o sangue correndo em nossas veias, como um circuito.

É nesta busca em que nos encontramos.

Independente da técnica ou do estilo, a performance do ator deve IRRADIAR. Deve ir além do limite demarcado pela pele. É por isto que Michael Chekhov entra no campo de investigação deste projeto. Porque ele propõe a irradiação como uma das qualidades físicas que o ator precisa trabalhar. Sua técnica tem por objetivo a visibilidade dos movimentos internos do ator por meio do corpo, tomando como ponto de partida o processo criativo corporal. Além disso, a técnica de Chekhov apela à consciência dividida do ator, refletindo e reconhecendo as reações físicas que se produzem internamente, por intermédio do registro consciente. Para Chekhov, o ator em cena deve estar permanentemente em estado de irradiação: “A irradiação é a capacidade de emitir a essência invisível de qualquer qualidade, emoção ou pensamento que queiramos. Deve emitir-se com grande intensidade. A irradiação é uma atividade de nossa vontade" (CHEKHOV, 1999, p. 57). ${ }^{1}$

Para alcançar este estado de irradiação, propomos a atuação como espaço de suspensão. O ator contido, suspenso em algum momento dramático, em um tempo ficcional, fora do tempo cotidiano, detém-se na cena e, como um acorde de violino, estende-se, dilata-se, suspende-se, produzindo inúmeros sentidos para a imaginação do espectador.

Por isso, estudaremos e conceberemos como base do trabalho atoral o silêncio, a pausa, a repetição, a detenção, a suspensão, a contenção e a irradiação. Investigando e submergindo-nos em uma busca detalhada e minuciosa, lenta e tranquila, pois acreditamos que a diferença entre uma e outra atuação depende do nível de profundidade dos detalhes. Nestes tempos, tudo é veloz e descartável, e a atuação deve sobreviver como arte: "O teatro é o ator. O que diferencia o homem comum do ator é a potencialização e a sua capacidade de interpretação com outras almas que não é a sua: a transfiguração" (JANUZELLI, 1992, p. 75).

O atuante deve transportar o espectador a outros lugares, para mobilizá-lo e dar-lhe o que pensar e sentir. Deve aproveitar essa disposição do espectador para fazê-lo voar, suspender-se em comunhão com a cena, abrindo-lhe outros canais de percepção, por meio de uma energia desconhecida, sedutora e não cotidiana, da qual ele não está. Esta energia o desloca e o convida, situando-o em outro estado de racionalidade. 
O atuante deve aprender a atuar desenvolvendo praticamente a habilidade da suspensão, do não cotidiano, como também propõe Eugenio Barba. O corpo cênico do atuante deve trabalhar para alcançar outra dimensão e, para isso, é preciso treinar. O corpo do atuante como lugar de detenção, estudo e reflexão, que mostra a outro ser, e que nele podemos ver seus pensamentos e sentimentos, o oculto.

\section{Objetivos Gerais}

1. Elaborar uma proposta metodológica que traga ao atuante procedimentos técnicos de trabalho, que permitam aprofundar e desenvolver a exteriorização das ações ou movimentos internos do corpo humano, por meio do trabalho corporal, para a criação tanto de pessoas fictícias quanto de estados dramáticos;

2. Desenvolver uma proposta pedagógico-artística que faça interatuar a prática dos procedimentos propostos por Michael Chekhov e os conceitos do movimento simbolista, na busca de uma forma de atuação comprometida com o aprofundamento dos movimentos internos do ser humano, enfatizando a verticalização dos processos criativos do ator.

\section{Objetivos Específicos}

1. Aprofundar teórica e praticamente os conceitos do método de treinamento para o ator desenvolvido pelo russo Michael Chekhov, que consistem, principalmente, em fisicalizar as reações produzidas internamente no trabalho do ator;

2. Difundir a técnica de Michael Chekhov, que é pouco praticada na América Latina;

3. Pesquisar os conceitos do Teatro Simbolista de Maurice Maeterlinck, seu maior expoente, particularmente o pensamento simbolista referente à atmosfera e aos conceitos de Teatro ou Drama Estático, que entende o teatro como arte reveladora da alma humana;

4. Provocar no ator suas próprias criações, estimulando a formação de uma linguagem autoral, baseada na individualidade criativa de cada ator;

5. Ampliar as habilidades do corpo do ator para uma linguagem extracotidiana, por meio de procedimentos técnicos corporais. 


\section{Algumas Considerações}

O Simbolismo como movimento literário apareceu no fim do século 19 em resposta ao excesso de realismo e naturalismo na arte. Foi uma reação contra os valores do materialismo e do pragmatismo na sociedade de então; uma maneira de reivindicar uma busca interior que não só concebia imagens reais e objetivas, mas também bebia dos sonhos e pesadelos como meio de expressão da realidade. A fantasia, a intimidade e a subjetividade são exaltadas, substituindo a objetividade do Realismo. O Simbolismo chegou a ser considerado o lado escuro do Romantismo, porque procurava o mais recôndito e obscuro das almas humanas, como forma de revelação do verdadeiro ser. É por intermédio de todas essas angulações que se pretende estudar o Simbolismo, estabelecendo uma conexão com a época atual. O que aconteceria hoje se nos voltássemos ao interior do ser humano, revelando essa interioridade por meio do corpo do ator?

Supomos que estas devem ser as indagações e encaminhamentos para o teatro na contemporaneidade. Deve-se entregar ao espectador uma possibilidade de não ser como tudo o que está fora dele. É necessário que o teatro seja um espaço do silêncio, onde se remexa o interior de cada espectador e de cada ator. Apelar tanto para a sua sensibilidade quanto para sua razão. Dirigindo-se, simultaneamente, à consciência e ao inconsciente do espectador, para despertar outras camadas de sua subjetividade. E, para este tipo de teatro, precisa-se de um ator treinado, que consiga exteriorizar o que se passa ao nível interno: pensamentos e sentimentos que o movem, a repercussão dos fatos em seu interior de um modo concreto. Não se trata de copiar o detalhe realista, e sim de tornar visível, presente, um estado dramático.

Michael Chekhov foi um ator russo, sobrinho de Anton Chekhov e aluno de Stanislavski, considerado por este como um dos seus melhores pupilos. Michael Chekhov se rebelou diante do Realismo de Stanislavski, assim como também o fez o Simbolismo. Chekhov queria uma atuação comprometida do ator, abrangendo tanto o seu corpo quanto sua individualidade criativa. Ele afirmava que o ator poderia ir além do texto do dramaturgo e do diretor; poderia ele mesmo CRIAR.

O método de Chekhov não é muito conhecido. Está publicado em português apenas o livro Para o ator (1986). Em espanhol, há somente duas obras: Sobre la técnica de la actuación (1999) e Lecciones para el actor profesional (2006). Em inglês, sua bibliografia é muito mais extensa. Por isso, torna-se de vital importância o estudo do trabalho de Chekhov. Ele chegou a utilizar suas técnicas apenas com o objetivo de formação do ator, como parte do treinamento atoral. Nesta 
pesquisa, pretende-se ir para além de suas técnicas de treinamento e levá-las até o campo da criação cênica. É estranho pensar que o método de Stanislavski seja ainda ensinado nas escolas de teatro, enquanto que a técnica de Chekhov (que consideramos uma proposta mais concreta, apreensível no corpo) não seja praticada.

Também cabe assinalar que aqui, no Brasil, especificamente no Rio de Janeiro, há apenas uma única pessoa que trabalha a técnica de Chekhov na América Latina, Hugo Moss. No desenvolvimento desta pesquisa, pretende-se entrevistá-lo e participar de suas aulas, para aprender e enriquecer a prática que estamos desenvolvendo de maneira autodidata.

Esta pesquisa encontra-se na interação entre as experiências do ator, a técnica de Chekhov, o silêncio e o Simbolismo. A mistura desses materiais vai compor um único material. Esteticamente, buscaremos uma cena desprovida de música exterior, sem elementos que possam distrair o olhar do espectador, sendo o ator o alvo da atenção, uma cena crua.

Também será mencionado o diretor francês Claude Régy que, supomos, sintetiza as ideias simbolistas no teatro contemporâneo, intensificando-as a partir de sua obsessão pelo silêncio. Em seu teatro, Régy trabalha os estados da alma, o claro-escuro na iluminação, a não ação do corpo, o "estar" e o silêncio, muito silêncio. A atmosfera onírica e a respiração como elementos dramáticos. Nenhum de seus livros está traduzido em português ou em espanhol.

A atuação não é um processo descartável. Ela precisa de tempo para chegar a algo fora de série, fora do que habitualmente estamos acostumados a ver. Como dizia Chekhov: fazer algo como nunca ninguém o tenha feito, atuar como ninguém. Ou seja, uma “individualidade criativa". Tentaremos conseguir nossos objetivos iniciando o processo prático, no qual eu serei a atrizpesquisadora. Construiremos cenas a partir de microcenas, ficando bastante tempo na criação de uma só sequência, promovendo a repetição e o “estar" em cada ação, para a busca inesgotável de recursos e registros de reações que possam aparecer.

Aprofundar, repetir, registrar; voltar a aprofundar, revisar, pensar; voltar a fazer, desfazer, refazer, provar. Sempre trabalhar e retornar ao já trabalhado, por um tempo determinado, depois trocar para logo regressar. A partir de uma só ação, podemos expandi-la ao universo da imaginação e da criatividade. $\mathrm{O}$ que se pretende propor é uma contribuição à formação do ator, entregar uma possibilidade de expansão e fazer crescer a arte da atuação, nossa arte, com uma função claramente pedagógica, sem deixar de lado um olhar artístico sobre o teatro. 
Revista "AspaS" - № 1 - 2011 - Anais do Primeiro Seminário de Pesquisas em Andamento

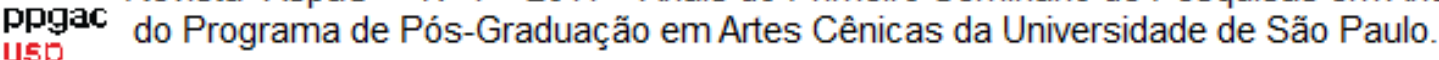

\section{Referências}

CHEKHOV, Michael. Para o ator. São Paulo: Martin Fontes, 1986.

. Sobre la técnica de la actuación. Barcelona: Alba Editorial, 1999.

The path of the actor. London: Routledge, 2005.

. Lecciones para el actor profesional. Barcelona: Alba Editorial, 2006.

JANUZELLI, Antonio Dias. Princípios básicos da preparação do ator para o espetáculo teatral. Dissertação (Mestrado em Artes Cênicas) - Escola de Comunicações e Artes, Universidade de São Paulo, São Paulo, 1984.

. A aprendizagem do ator. Editora Ática, 1986.

Oficio do ator e o estagio das transparências. Tese (Doutorado em Artes Cênicas) -

Escola de Comunicações e Artes, Universidade de São Paulo, São Paulo, 1992.

STANISLAVSKI, Constantin. Minha Vida na Arte. São Paulo. Anhembi, 1956.

. A construção da personagem. Rio de Janeiro: Civilização Brasileira, 1970.

. A criação do papel. Rio de Janeiro: Civilização Brasileira, 1972.

. A preparação do ator. Rio de Janeiro: Civilização Brasileira, 1964.

\footnotetext{
${ }^{1}$ Tradução nossa.
} 